\title{
10 DifFICULTIES IN IMPLEMENTING THE AGILE SUPPLY CHAIN: Lessons Learned from Interorganizational Information Systems Adoption
}

\author{
Akos Nagy \\ Tilburg University \\ Tilburg, THE NETHERLANDS
}

\begin{abstract}
Agility is becoming an important component in the continuous stmiggle to increase overall supply chain performance. The need to react speedily to sudden changes in demand or supply necessitates the sharing of a large amount of high quality information in a timely manner between trading partners. Electronic data interchange (EDI) and other interorganizational systems (IOS) are able to support these goals; however, the diffusion of these systems throughout the supply chain is by no means guaranteed. We borrow from the IOS adoption literature to explain reasons of failure to adopt. We use the adoption position model to analyze three short case studies and we corroborate that, in these cases, the relative power of a firm and its intent of adoption toward a specific IOS together determine its position in the decision. By combining the adoption positions of the trading partners, we can effectively predict the decision of the outcome. At the end of the paper, we propose strategies to overcome these barriers which hinder the realization of an agile supply chain.
\end{abstract}

Keywords Agile supply chain, interorganizational information system, adoption, adoption position, power

\section{INTRODUCTION}

\subsection{The Agile Supply Chain}

Establishing effective supply chain strategies became paramount in today's market environment where technological developments, increasing competition, and ever more 
demanding customers necessitate the supply chain to be more efficient. The reduction of costs by eliminating waste and delays and the simultaneous improvement of customer satisfaction is the goal of supply chain performance initiatives (Christopher and Towill 2001). This philosophy is the center point of the lean approach, which was extended by Womack and Jones (1996) to include the suppliers of an organization where they envisioned the seamless flow of goods throughout the whole value chain, eventually creating a lean enterprise.

The lean concept works well where demand is relatively stable and hence predictable and where variety is low. However, where demand is volatile and the variety of customer requirements is high, an agile design is needed (Christopher 2000). Agility has been defined in many different ways in the literature and often the difference between agility, leanness, and flexibility is not clear. We adopt the definition of Conboy and Fitzgerald (2004) on agility, which is the result of a meta-analysis and reflects the differences between these terms:

Agility is the continual readiness of an entity to rapidly or inherently, proactively or reactively, embrace change, through high quality, simplistic, economical components and relationships with its environment.

According to Mason-Jones et al. (2000), the agile design of a supply chain is most important where not the costs, but the service level decides on who the market winner is. Lee (2004) goes further and states that being agile is only one of the three qualifiers of a sustainable advantage next to being able to adapt over time to changing market conditions and to align interests of all firms in the supply network.

\subsection{From Information Technology Diffusion to Adoption}

In order to realize agility in supply chains, companies have to adapt a different mindset where they have a high priority on production schedule and where they utilize the concepts of quick response and continuous replenishment (Christopher et al. 2001). Such practices are able to diminish the bullwhip effect (Morell and Ezingeard 2002), which is the amplification of demand order variability as orders move up the supply chain (Lee et al. 1997). This approach requires that communication at all levels of the supply chain must be effective and timely; therefore, information systems become necessary components of a successful supply chain design. Interorganizational information systems (IOS), refer to computer and telecommunications infrastructure developed, operated, and/or used by two or more firms for the purpose of exchanging information that supports a business application or process ( $\mathrm{Li}$ and Williams 1999). IOS enable higher visibility between trading partners and support the struggle to lower demand uncertainty. In the context of supply chains, they enable integration between trading partners through faster, more-efficient, and more-accurate data exchange, thus offering ample benefits for companies (Bakos 1998; Banerjee and Golhar 1994; O'Callaghan et al. 1992; Vlosky et al. 1994; Von Heck and Ribbers 1999).

The diffusion of a technology is the process by which an innovation is communicated through certain channels over time among the members of a social system 
(Rogers 1995). Diffusion speeds up in the presence of positive network effects (Teo et al. 2003) or an industry-wide regulatory body or when a critical mass of adopters (Somasundaram 2004) is reached. The ideal scenario of supply-chain-wide diffusion of IOS, however, does not happen very often.

To find the reasons behind these failures, we seek understanding through the adoption decision of each individual organization. By utilizing the model of Nagy (2004) on IOS adoption, we try to answer the following research questions through case studies:

- Why does the adoption of IOS fail in supply chains?

- What strategies could help firms to overcome the barriers of adoption of the IOS in order to realize an agile supply chain?

\section{ADOPTION IN THE IOS LITERATURE}

Research on the adoption of IOS already has a long history. Electronic data interchange (EDI) has been used for more than 30 years now (Stefansson 2002) to exchange structured data electronically in a standardized format between organizations (O'Callaghan and Turner 1995) and has been intensively researched since the mid-1980s (Chan and Swatman 1998; Somasundaram and Karlsbjerg 2003).

The diffusion of IOS can be analyzed at three different levels: the micro level analysis focuses on characteristics of individuals and/or organizational units, the macro level on industry-wide or national regulatory bodies, while the meso level in between the two concentrates on networks of interacting agents (Damsgaard and Lyytinen 1998). What makes IOS an interesting technology to study is that it requires two or more organizations to agree upon its implementation; therefore, an adoption decision depends heavily on the other parties (Chan and Swatman 1998), necessitating co-adoption of the technology (Nelson et al. 2002). Socio-political factors, such as interfirm power relationships and trust, come in to play an important role in the decision-making process.

This paper focuses on the dyadic relationships of trading partners (placing the research on the meso level) and on the reasons of success and failure to co-adopt IOSs.

As competition moves from individual firm level to the level of supply chains, there is an increasing need for a seamless flow of information between supply chain partners. Unfortunately, the assumption of unproblematic IOS integration often found in modular supply chain research (Von Liere et al. 2004) is unrealistic. Firms act strategically when they decide not to adopt a certain IOS (Bouchard 1993); therefore, we assume that companies act rationally and estimate not only the benefits (Chwelos et al. 2001; Jones and Beatty 1998), but also the perceived costs (Nagy et al. 2004) and perceived risks (Kumar and van Dissel 1996) of an IOS project. The costs and risks of IOS implementation have often been cited as potential barriers of adoption just as well as social factors such as lack of trust (Hart and Saunders 1997) and lack of coordination and cooperation (Tan and Raman 2002).

In recent years, research on the role of power in information systems has gained momentum as the interest of researchers increased to study behavioral factors as well as purely rationalistic ones (Jasperson et al. 2002). Power relations have been studied on the individual, group, organizational, and interorganizational levels. In this paper, we are interested in the last category and define power as a firm's ability to influence 
change in another organization that is dependent upon that firm's resources (Hart and Saunders 1998)

Nagy (2004) criticizes the IOS literature for not handling the role of power relations between supply chain partners properly. His main critique is that power in the literature always appears to have a positive effect on adoption (as external pressure), however an inhibiting effect could also be theorized. This paper develops the adoption position model, which tries to overcome this biased view on the role of power and give a more complete explanation on the adoption phenomenon. We are going to apply this model through case studies to show how the (lack of) co-adoption of an IOS contributes to the realization of an agile supply chain.

\section{THE ADOPTION POSITION MODEL}

\subsection{Description of the Model}

The main advantage of the model is that it takes into account both the economic and social factors of the decision-making process and by doing this it becomes possible to separate the intention of adoption from the actual ability of the firm to control that decision. Firms do not operate in a vacuum they are part of a larger supply network where certain power structure is present (Cox et al. 2002). Power is defined as the capability of a firm to exert influence on another firm to act in a prescribed manner (Hart and Saunders 1997). This influential effect, however, has only been utilized in IOS research as an enabler to adoption and it is mostly part of the intention construct (Chwelos et al. 2001), giving an incomplete view on adoption.

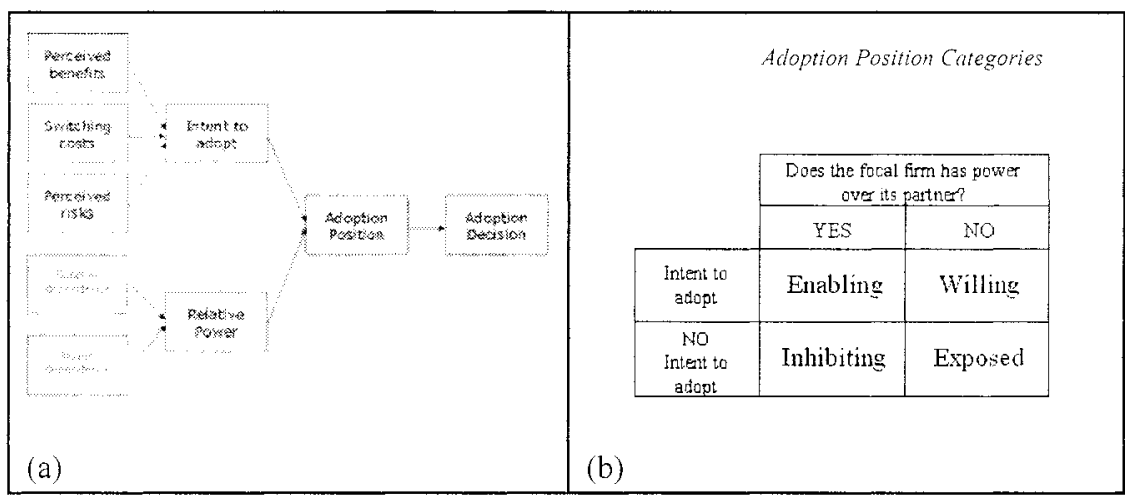

Figure 1. The Adoption Position model (Source: A. Nagy, "The Effect of Power on the Adoption of Interorganizational Information Systems: The Adoption

Position Model," Proceedings of the $12^{\text {th }}$ European Conference on Information Systems, 2004) 
Figure la presents the model. The adoption decision is the function of the combined adoption position of the two trading partners that are negotiating over a proposed IOS. There are four possible adoption positions into which a company can be categorized based on its intention to adopt and its relative power over its partner (Figure $\mathrm{lb}$ ). An enabling firm is interested in the adoption and has influence over its trading partner; therefore, even when the partner is resistant, it can use its power in different ways to try to make the implementation come true. Note that being in an enabling position does not guarantee that the IOS adoption will occur; instead it only gives the possibility for the firm to try to start the project.

A firm that is interested in the adoption of a certain IOS but has no power over its trading partner is termed as being in a willing adoption position. The willing firm perceives a net positive return on the investment and is willing to share information through the intended electronic linkage, but it is not able to force its trading partner into the adoption. A firm with an inhibiting position sees no interest in implementing and using the proposed IOS and it has the power to create a barrier to adoption. Those firms that fall into the last quadrant are less fortunate; they see no interest in the adoption and they have no leverage over the trading partner; therefore, they are dependent on the partner's position. Their adoption position is called exposed.

Having determined the adoption position of a focal firm, however, still does not make it possible to predict the outcome of the adoption decision. The cause of this ambiguity is the way power positions are categorized between two firms. Cox (1997) proposes the so-called power matrix as a typology of power relationships between two firms. Next to the two cases where one of the partners dominates (supplier dominance or buyer dominance), the parties involved can be also interdependent or independent. This means that knowing that the buyer has power is still not enough information to decide whether it is a case of buyer dominance or interdependence. This method, therefore, necessitates the analysis of dependence from both sides of the dyad.

When we apply the adoption position model to both parties in a dyadic relationship, we get 16 possible combinations on the position of the supplier and the buyer (see Figure 2). This typology is addressed in a pair-wise way, such as enabling-willing or inhibiting-enabling where the words signify the adoption position of the supplier and the buyer, respectively.

\begin{tabular}{|c|c|c|c|c|c|}
\hline & \multicolumn{4}{|c|}{ Buyer's adoption position } \\
\hline & & Enabling & Willing & Inhibiting & Exposed \\
\hline \multirow{4}{*}{ 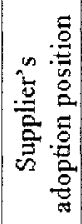 } & Enabling & + & + & $+1-$ & + \\
\hline & Willing & + & + & - & $?$ \\
\hline & Inhibiting & $+\%$ & - & - & - \\
\hline & Exposed & + & $?$ & - & - \\
\hline
\end{tabular}

Figure 2. Adoption Positions in a Dyadic Relationship and Propositions for the Outcome of the IOS Adoption 
At the intersection of each combination is a proposition for the success of the IOS adoption. A "+" sign means that the particular adoption position pair will hypothetically support the adoption, while a "-." marked pair does not. In the case of "+1-" the interdependent parties have opposing intentions and the decision is not straightforward. The "?" sign refers to the equivalently ambiguous outcome of the decision when the parties have opposing intention but neither has the leverage to influence the other.

\subsection{Operationalization of the Constructs}

Intent to adopt is operationalized as perceived benefit (the anticipated advantages that the IOS can provide for the organization) (Chwelos et al. 2001), perceived risks (Kumar and van Dissel 1996), and switching costs. Switching cost is defined as the cost incurred by the organization when deciding to adopt a new IOS compared to the current technological and operational level. We distinguish costs incurred from the infrastructure, application, and business process levels (Nagy et al. 2004).

Relative power is operationalized based on Cox et al. (2002), where the authors combine the work of Emerson (1962) with the resourced based view (Barney 1991) to determine critical assets in an organization. These critical assets are defined as supply chain resources that combine high utility with relative scarcity in a buyer-supplier exchange and in a market context. We use the concept of critical assets to measure dependence and to determine the power relationship between the trading partners. For a listing of the detailed operationalization of the constructsm see Appendix A.

\subsection{Reasons of Failure}

According to this model, the adoption of IOS and, therefore, the closer integration of a dyadic section of a supply chain could fail in two basic scenarios: (1) one party has no intention to adopt the technology and the other has no power to coerce or otherwise impose its will on its partner; (2) one party has no intention to adopt the IOS and is not dependent on the initiator; therefore, that party has the power to say no and act as an inhibitor.

Several factors can lead to the lack of intention: the company does not see the benefits in the technology or it does not perceive added value by adopting another IOS in the case where it already has a different system in place with other trading partners. Costs of implementing an IOS could discourage firms, especially when it necessitates change in business processes. The perception that the investment has a high risk on the technical, operational, or strategic level negatively affects the intention to adopt as well (Hughes et al. 2004). Such risks are that the technology will become obsolete (Kumar and van Dissel 1996), the trading partner will act opportunistically, the IOS has a high asset specificity (Williamson 1979), and the possibility of getting locked in (Lonsdale 2001). 


\section{COMPARATIVE CASE STUDIES}

In this section, we are going to apply the adoption position model in a qualitative way through case studies (both from primary and secondary source) to show how the (un)successful co-adoption of an IOS led to the (un)successful realization of agility in supply chains.

\subsection{Case 1: Inhibiting-Willing Relationship}

The description of the case is based on the case study by Ribbers (1995). Lumiance $\mathrm{BV}$ is a supplier of lighting fixtures in the Netherlands. Its core activities are design, purchasing of piece parts, and distribution. The assembly of the fixtures had been sourced out to another company. The total assortment comprised 500 article numbers. The piece parts were bought from 100 suppliers.

Technische Unie (TU) was one of Lumiance's most important customers in the Netherlands, purchasing all 500 articles. The TU-initiated EDI project first failed because of the lack of technical readiness at Lumiance. The project had been delayed by two years. In 1992, the second run met with another problem. Lumiance could not introduce the purchase order confirmation message because it did not have the right organization for inventory control. Inventories for Dutch and international customers were not separated, neither physically nor at the information level. The key was to implement the standard EAN barcoding system to be able to universally identify the stock items. The company would not mind introducing the EAN code, although it had its own four-digit article code. It was planned to expand the system to Lumiance's own suppliers

To make the system work smoothly, it was important to get the suppliers to adopt the EAN coding system and standard packaging units also had to be introduced. Lumiance's suppliers, however, were strongly opposed to the EAN code system due to their already installed bar coding systems and information systems. Compliance with the EDI proposal would have required substantial investments in changing their infrastructure, applications, and business processes. Therefore, there was clearly no intention to adopt the system. Lumiance did not have the power to make the suppliers invest more in additional systems and change the existing business processes in either a coercive or a persuasive way. The opposition of a powerful supplier (inhibiting position) hindered Lumiance's integration efforts (willing position).

\subsection{Case 2: Willing-Inhibiting Relationship}

This example of a failed supply chain integration is based on Gregor and Menzies (2000). In the Australian beef industry, supply chain management requires producers to commit to the production of quality meat according to agreed specifications, including documented feeding strategies and animal health inputs, trace-back procedures, and even taste tests to ensure their product meets the expectations and the promise of the retailer. 
Effective supply chain management in the beef industry would put the industry in a better position to compete with other industries, such as pork and chicken.

The need for compliance with the individually identifiable cattle regulation has forced the implementation of the National Livestock Identification Scheme (NLIS), which will enable greater trace-back to property of origin in case of disease or chemical residue scares. Such a system necessitated the implementation of EDI. Within the processing industry, there are a number of hardware and software systems currently in use. A number of privately owned companies had established their own methods of collecting information, but there was still little interconnectivity between processors and farms.

The establishment of the national identification system was stalled because the processors were not willing to provide feedback as part of that system. Processors did not wish to cooperate because it would provide the producer with increased data analysis and comparison opportunities that could work to the disadvantage of the processors. Also, the meat processors were using computer systems that did not transmit in the industry standard file format.

There is a buyer dominant power structure in the Australian beef industry, where the main source of power is that a large supplier pool of small firms is faced by a small pool of large buyers. Switching and searching costs for buyer are low and, in this sector, vertical integration is also a threat. The perceived benefit of a higher level of integration is low for the powerful buyer, because more extensive information sharing and visibility would shift the power toward the supplier. The lack of an industry body that owns the problem forced the less powerful producers to initiate the project (willing position), but they could not make the buyers (inhibiting position) integrate their systems or create a more effective supply chain.

\subsection{Case 3: Exposed-Enabling Relationship}

The previous cases were examples of failures of IOS adoption that caused the supply chain to be less effective than it could have been. Individual interests of supply chain members sometimes work against the interest of the supply chain in which they operate when the power structure enables them to do so. Power relationships can also be in favor of establishing a more agile supply chain when the dyads form supportive adoption positions (see Figure 2). We conducted this case study during the year 2002.

Bakkersland Easy Bakery is a large producer of bread and bakery products and also cake, deep-frozen, and fast-food products in the Netherlands. It employs 2,700 people. The market for bakery products consists of 6.8 percent of the total food industry. The company owns 26 plants in the Netherlands and has a sales organization in several European countries (Belgium, Germany, France, Spain and Italy) and it also exports to the United States.

Bakkersland has over 100 suppliers of raw materials, mainly from the Netherlands and from Belgium, and a few others for packaging material from outside the Benelux countries. On the customer side, distribution creates an even more complex network not only because of the number of customers (approximately 60 ), but also the existence of different distribution channels. Most of the products are shipped to distribution centers 
owned by the supermarket chains. There are 20 supermarket chains operating in the Netherlands and all of them have their own warehouses. Third-party logistics service providers carry out the transportation. Other distribution channels include independent warehouses, sales agents (across Europe and in the United States), direct sales to restaurants, and sales through company-owned retail pastry stores and outlets. Approximately 85 percent of all the production goes to retail.

A large retailer (call it Retailer) was the first retail chain in the industry that initiated the implementation of EDI with its suppliers. Retailer pushed the suppliers to adopt EDI through a value-added network, but it employed a persuasive strategy where Retailer demonstrated the use of the system to the suppliers. Retailer wanted to minimize its inventory level in the stores to virtually zero. In order to achieve this, it wanted to implement the concept of vendor managed inventory (VMI) under the so called "comakership policy," where the supplier gains access to inventory levels and control over replenishment.

Bakkersland, however, did not see the benefits of the system. With their current information systems in place, they have already achieved a 99.4 percent service level and they did not believe that the new process was well suited for their current ERP system. From Bakkersland's viewpoint, the VMI would only put additional burdens on them in the form of costs and responsibility.

The relationship was clearly buyer dominance despite the size of Bakkersland. About 25 percent of their total sales went to Retailer, which in fact has the largest market share in the Netherlands. The product is highly substitutable on a very competitive market. The EDI system was eventually implemented.

We can conclude that Bakkersland and Retailer formed an exposed-enabling adoption position pair, which led to the adoption of the system and the realization of a more agile supply chain, despite the fact that the supplier did not have the intention to do it.

\section{REMEDIES AND STRATEGIES}

What strategies are available for an organization that wishes to introduce higher agility in its supply chain, but has not been able to do so, because it failed to implement an IOS with its trading partner(s)? We can use the adoption position model to answer this question as well. Figure 2 showed those adoption position pairs supportive of an IOS adoption decision. The company that wishes to implement a system with its trading partner, therefore, first has to evaluate the relationship and position itself and its partner in the matrix of Figure $1 \mathrm{~b}$. There are two ways to change the unfavorable position to a favorable one: either the focal firm has to persuade its trading partner to use the system or it has to increase its power level.

By increasing the benefits or lowering the barriers of adoption, the focal firm can positively change the intention of its trading partner. Piderit (2000) found that lowering barriers is more effective. Barriers, such as switching costs of the partner (Nagy et al. 2004), to the new system can be lowered by using standardized applications that can integrate more easily into existing IT architecture or by jointly planning shared business processes, which will require less business process redesign (Nelson and Shaw 2003). 
The second strategic direction for an initiator of an IOS project is to increase its power base or to increase the dependence of the partner firm. This is much harder to achieve as it is often requires the redesign of the supply chain (vertical integration, disintermediation of intermediaries) or making significant changes in one's own business (higher value proposition for partner through increased commercial or operational importance; Cox et al. 2002) or by introducing new governance mechanisms (quasi integration and participation in joint decision making; Subramani and Venkatraman 2003).

It is important to note that higher power does not necessarily mean that it has to be used coercively. Power can be exercised in a persuasive way as well or the mere potential of having power can influence adoption (Hart and Saunders 1997). Helping suppliers develop the necessary capabilities to adapt to new business requirements (Krause et al. 1998) will establish trust in the relationship. This increased trust will lower the perceived risks of the IOS and create a positive intention toward adoption.

Thus a self-assessment of relative power of a firm will result in different negotiation strategies. A relatively more powerful firm might choose to coercively influence the behavior of its trading partner or it could try to persuade with a softer approach. A weaker firm could anticipate the requirements of a more powerful partner and employ a proactive strategy (Webster 1995). So far, the paper assumes a single relationship between supply chain members; however, these relationships are often multi-faceted (Wiseman 1988). In such situations firm A might be dependent on firm B on one side, but could have the upper hand on another. Negotiation strategies become even more important in these cases, but a further discussion is beyond the scope of this paper.

\section{CONCLUSION}

Information technology is an essential component of effective supply chain management; therefore, by studying interorganizational systems we can contribute to the agility literature.

We have demonstrated through three short case studies that the adoption of IOS can have significant effects on the efficiency of supply chains. The cases suggest that the electronic exchange of information between trading partners not only depends on their intention to adopt the system, but on the underlying power structure as well. A conflict of interest in IOS adoption coupled with an unsupportive power structure could lead to inefficiencies in the supply network and can indirectly thwart the efforts to realize an agile supply chain. These preliminary results suggest that research on agility should not neglect the effect of power relations in business networks.

Using the adoption position model, we were able to explain why the co-adoption of IOS fails or succeeds. However, the small number of cases does not validate completely our model, therefore further case studies need to be conducted to tests the hypotheses.

By estimating the adoption position of both parties in a dyadic relationship, one could predict the outcome of the adoption decision. This has important implications for both researchers and practitioners: Researchers would be able to map entire supply chains and examine the prospect of supply-chain-wide diffusion of a technology. Practitioners could benefit from the model by establishing a clearer view over their company's position in the supply chain and evaluating project proposals on different IOSs. 


\section{REFERENCES}

Bakos, Y. "The Emerging Role of Electronic Marketplaces on the Intemet," Communications of the ACM (41:8), 1998, pp. 35-42.

Banerjee, S., and Golhar, D. Y. "Electronic Data Interchange: Characteristics of Users and Nonusers," Information and Management (26:2), 1994, pp. 65-74.

Barney, J. "Firm resources and sustained competitive advantage," Joumal of Management (17:1), 1991, pp. 99-120.

Bouchard, L. "Decision Criteria in the Adoption of EDI," in Proceedings of the $14^{\text {th }}$ International Conference in Information Systems, J. I. DeGross, R. P. Bostrom, and D. Robey (Eds.). Orlando, FL, 1993, pp. 365-376.

Chan, C., and Swatman, P. M. C. "EDI Implementation: A Broader Perspective," in Proceedings of the $/ l^{\text {th }}$ International Conference on Electronic Commerce, Bled, Slovenia, 1998, pp. 90-108.

Christopher, M. "The Agile Supply Chain: Competing in Volatile Markets," Industrial Marketing Management (29:1), 2000, pp. 37-44.

Christopher, M., and Towill, D. "An Integrated Model for the Design of Agile Supply Chains," International Joumal of Physical Distribution and Logistics Management (31:4), 2001, pp. 235-246.

Chwelos, P., Benbasat, I., and Dexter, A. S. "Research Report: Empirical Test of an EDI Adoption Model," Information Systems Research (12:3), 2001, pp. 304-321.

Conboy, K., and Fitzgerald, B. "Toward a Conceptual Framework of Agile Methods," paper presented at XP Agile Universe, Calgary, Alberta, 2004.

Cox, A. "On Power, Appropriateness and Procurement Competence," Supply Management, October 1997, pp. 24-27.

Cox, A., Ireland, P., Lonsdale, C., Sanderson, J., and Watson, G. Supply Chains, Markets and Power: Mapping Buyer and Supplier Power Regimes, London: Routledge, 2002.

Damsgaard, J., and Lyytinen, K. "Contours of Diffusion of Electronic Data Interchange in Finland: Overcoming Technological Barriers and Collaborating to Make it Happen," Journal of Strategic Information Systems (7:4), 1998, pp. 275-297.

Emerson, R. M. "Power-Dependence Relations," American Sociological Review (27), 1962, pp. $31-41$.

Gregor, S., and Menzies, D. "Electronic Data Interchange and Supply Chain Management: A Case Study of the Beef Industry," working paper, Central Queensland University, 2000.

Hart, P., and Saunders, C. "Emerging Electronic Partnerships: Antecendents and Dimensions of Edi Use from the Supplier's Perspective," Journal of Management Information Systems (14:4), 1998, pp. 87-111.

Hart, P., and Saunders, C. "Power and Trust: Critical Factors in the Adoption and Use of Electronic Data Interchange," Organization Science (8:1), 1997, pp. 23-41.

Hughes, M., Powell, P., Panteli, N., and Golden, W. "Risk Mitigation and Risk Absorption in IOS: A Proposed Investigative Study," in Proceedings of the $12^{\text {th }}$ European Conference on Information Systems, T. Leino, T. Saarinen, and S. Klein (Eds.), Turku, Finland, 2004, pp. $1-8$.

Jasperson, J., Carte, T. A., Saunders, C., Butler, B. S., Croes, H. J. P., and Zheng, W. "Review: Power and Information Technology Research: A Metatriangulation Review," MIS Quanterly (26:4), 2002, pp. 397-459.

Jones, M. C., and Beatty, R. C. "Towards the Development of Measures of Perceived Benefits and Compatibility of Edi: A Comparative Assessment of Competing First Order Factor Models," European Journal of Information Systems (7:3), 1998, pp. 210-220. 
Krause, D. R., Handfield, R. B., and Scannel, T. V. "An Empirical Investigation of Supplier Development: Reactive and Strategic Processes," Journal of Operations Management (17:1), 1998, pp. 39-58.

Kumar, K., and van Dissel, H. G. "Sustainable Collaboration: Managing Conflict and Cooperation in Interorganizational Systems," MIS Quarterly (20:3), 1996, pp. 279-300.

Lee, H. L. "The Triple-A Supply Chain," Harvard Business Review, October 2004, pp. 1-13.

Lee, H. L., Padmanabhan, V., and Whang, S. "The Bullwhip Effect in Supply Chains," Sloan Management Review (38:3), 1997, pp. 93-102.

Li, F., and Williams, H. "New Collaboration Between Firms: The Role of Interorganizational Systems," in Proceedings of the $32^{\text {nd }}$ Hawaii International Conference on System Sciences, Los Alamitos, CA: IEEE Computer Society Press, 1999, pp. 1-10.

Lonsdale, C. "Locked-in to Supplier Dominance: On the Dangers of Asset Specificity for the Outsourcing Decision," The Journal of Supply Chain Management (37:2), 2001, pp. 22-27.

Mason-Jones, R., Naylor, J. B., and Towill, D. "Engineering the Agile Supply Chain," International Journal of Agile Management Systems (2:1), 2000, pp. 54-61.

Morell, M., and Ezingeard, J.-N. "Revisiting Adoption Factors of Inter-Organizational Information Systems in SMEs," Logistics Information Management (15:1), 2002, pp. 46-57.

Nagy, A. "The Effect of Power on the Adoption of Interorganizational Information Systems: The Adoption Position Model," in Proceedings of the $12^{\text {ih }}$ European Conference on Information Systems, Turku, Finland, 2004.

Nagy, A., Orriens, B., and Fairchild, A. "The Promise and Reality of Internet-Based Interorganizational Systems," in Proceedings of the IADIS International Conference eSociety, Avila, Spain, 2004, pp. 886-890.

Nelson, M. L., and Shaw, M. J. "The Adoption and Diffusion of Interorganizational System Standards and Process Innovations," in Proceedings of the MIS Quarterly Special Issue Workshop, Seattle, WA, 2003, pp. 258-301.

Nelson, M. L., Shoonmaker, M., Shaw, M. J., Shen, S., Qualls, W., and Wang, R. "Modularized Interoperability in Supply-Chains: A Co-adoption Study of RosettaNet's XML-Based InterOrganizational Systems," in E-Business Management: Integration of Web Technologies with Business Models, M. J. Shaw (Ed.), Boston: Kluwer Academic Publishers, 2002, p. 480.

O'Callaghan, R., Kaufmann, P. J., and Konsynski, B. R. "Adoption Correlates and Share Effects of Electronic Data Interchange Systems in Marketing Channels," Journal of Marketing (56:2), 1992, pp. 45-56.

O'Callaghan, R., and Turner, J. A. "Electronic Data Interchange: Concepts and Issues," in EDI in Europe: How it Works in Practice, H. Krcmar, N. Bjørn-Andersen, and R. O'Callaghan (Eds.), Chichester, England: John Wiley \& Sons Ltd.., 1995, pp. 1-19.

Piderit, S. K. "Rethinking Resistance and Recognizing Ambivalence: A Multidimensional View of Attitudes Toward an Organizational Change," Academy of Management Review (25:4), 2000, pp. 783-794.

Ribbers, P. M. "Purchasing Through EDI: The Case of Technische Unie in The Netherlands," in EDI in Europe: How it Works in Practice, H. Krcmar, N. Bjørn-Andersen, and R. O'Callaghan (Eds.), Chichester, England: John Wiley \& Sons Ltd.., 1995, pp. 47-84.

Rogers, E. M. Diffusion of Innovations ( $4^{\text {th }}$ ed.), New York: Free Press, 1995.

Somasundaram, R. "Operationalizing Critical Mass as the Dependent Variable for Researching the Diffusion of e-Marketplaces: Its Implications," in Proceedings of the $17^{\text {th }}$ Bled eCommerce Conference, Y-H Tan, D. Voge, J. Gricar, and G. Lenart (Eds.), Bled, Slovania, June 2004, pp. 1-14.

Somasundaram, R., and Karlsbjerg, J. "Research Philosophies in the IOS Adoption Field," in Proceedings of the II $I^{\text {th }}$ European Conference on Information Systems, C. Ciborra, R. Mercurio, M. De Marco, M. Martinez, and A. Carignani (Eds.), Napoli, Italy, 2003, pp. 1-11. 
Stefansson, G. "Business-to-Business Data Sharing: A Source for Integration of Supply Chains," International Joumal of Production Economics (75:1-2), 2002, pp. 135-146.

Subramani, M., and Venkatraman, N. "Safeguarding Investments in Asymmetric Interorganizational Relationships: Theory and Evidence," Academy of Management Journal (46:1), 2003, pp. 46-62.

Tan, M., and Raman, K. S. "Interorganizational Systems and Transformation of Interorganizational Relationships: A Relational Perspective," in Proceedings of the $23^{\text {rd }}$ International Conference on Information Systems, L. Applegate, R. Galliers, and J. I. DeGross (Eds.), Barcelona, Spain, 2002, pp. 877-884.

Teo, H. H., Wei, K. K., and Benbasat, I. "Predicting Intention to Adopt Interorganizational Linkages: An Institutional Perspective," MIS Quarterly (27:1), 2003, pp. 19-49.

Vlosky, R. P., Smith, P. M., and Wilson, D. T. "Electronic Data Interchange Implementation Strategies: A Case Study," Journal of Business and Industrial Marketing (9:4), 1994, pp. $5-18$.

Von Heck, E.., and Ribbers, P. M. "The Adoption and Impact of EDI in Dutch SME's," in Proceedings of the $32^{\text {id }}$ Hawail International Conference on System Sciences, Los Alamitos, CA: IEEE Computer Society Press, 1999, pp. 1-9.

Von Liere, D., Hagdorn, L., Hoogeweegen, M., and Vervest, P. H. M. "Organizational Performance of a Firm in a Modular Business Network," in Proceedings of the $12^{\text {ti }}$ European Conference on Information Systems, Turku, Finland, 2004.

Webster, J. "Networks of Collaboration or Conflict? Electronic Data Interchange and Power in the Supply Chain," Journal of Management Information Systems (4:1), 1995, pp. $31-42$.

Williamson, O. "Transaction Cost Economics: The Governance of Contractual Relations," Journal of Law and Economics (22:2), 1979, pp. 233-261.

Wiseman, C. Strategic Information Systems, New York: McGraw-Hill Professional, 1988.

Womack, J. P., and Jones, D. T. Lean Thinking: Banish Waste and Create Wealth in Your Corporation, New York: Simon \& Schuster, 1996.

\section{ABOUT THE AUTHOR}

Akos Nagy is a Ph.D. candidate in the Department of Information Systems and Management at Tilburg University, The Netherlands. He holds a M.Sc. in Information Systems from the Graduate School of the Center for Economic Research in Tilburg University. His research work has been presented at several international conferences. His current research interests are interorganizational information systems, supply chain management and performance, and the role of power in business networks. Akos can be reached at A.Nagy@uvt.nl. 


\section{APPENDIX A: OPERATIONALIZATION OF THE CONSTRUCTS}

\begin{tabular}{|c|c|}
\hline Constructs/Variables & Source \\
\hline $\begin{array}{l}\text { Perceived Benefits } \\
\text { Direct } \\
\text { Reduced transaction costs } \\
\text { Improved cash flow } \\
\text { Reduced inventory } \\
\text { Indirect } \\
\text { Improved information flow } \\
\text { Improved internal operations } \\
\text { Improved service } \\
\text { Improved trading partner relations }\end{array}$ & $\begin{array}{l}\text { Chwelos et al. } 2001 \\
\text { Jones and Beatty 1998) }\end{array}$ \\
\hline $\begin{array}{l}\text { Perceived Risks } \\
\text { Relation specific assets risk } \\
\text { Relation specific processes risk } \\
\text { Post contractual dependence } \\
\text { Information asymmetry risk } \\
\text { Loss of resource control risk } \\
\text { Loss of ordering elasticity } \\
\text { Use of sub-optimal practices } \\
\text { Risk of opportunism (Trust) } \\
\text { Technology risk }\end{array}$ & $\begin{array}{l}\text { Hughes et al. } 2004 \\
\text { Kumar and van Dissel } \\
\text { 1996 Lonsdale } 2001\end{array}$ \\
\hline $\begin{array}{l}\text { Switching Cost } \\
\text { Compatibility/Readiness } \\
\text { Infrastructure compatibility } \\
\text { Application compatibility } \\
\text { Business process compatibility } \\
\text { Specificity } \\
\text { Infrastructure change specificity } \\
\text { Application change specificity } \\
\text { Business process change specificity } \\
\text { Training }\end{array}$ & Nagy et al. 2004 \\
\hline $\begin{array}{l}\text { Supplier's Dependence on Buyer } \\
\text { Resource utility } \\
\text { Operational importance } \\
\text { Commercial importance } \\
\text { Substitutability } \\
\text { Buyer pool } \\
\text { Supplier's switching cost } \\
\text { Search cost } \\
\text { Threat of backward integration } \\
\text { Threat of intermediation } \\
\text { Cartel of buyers }\end{array}$ & $\begin{array}{l}\text { Barney } 1991 \\
\text { Cox et al. } 2002 \\
\text { Emerson } 1962\end{array}$ \\
\hline
\end{tabular}




\begin{tabular}{|l|l|}
\hline \multicolumn{1}{|c|}{ Constructs/Variables } & \multicolumn{1}{c|}{ Source } \\
\hline Buyer's Dependence on Supplier & Barney 1991 \\
Resource utility & Cox et al. 2002 \\
Operational importance & Emerson 1962 \\
Commercial importance & \\
Resource Scarcity & \\
Imperfect imitability & \\
Substitutability & \\
Threat of forward integration & \\
Threat of intermediation & \\
Cartel of buyers & \\
\hline
\end{tabular}

